\title{
ENTRE CORPO-INSTRUMENTO \\ E SUJEITO MULHER: RELAÇÕES \\ DIALÓGICAS EM UMA TIRINHA \\ DE QUINO
}

Wilder Kleber Fernandes de Santana ${ }^{1}$

Marcus Garcia de Sene ${ }^{2}$

Resumo: Este trabalho delimitou como objeto de estudo as relações dialógicas, categoria central no pensamento de Mikhail Bakhtin, em diálogo com outros integrantes do círculo de Bakhtin, como Valentin Volóchinov e Pável Medviédev. Para tanto, selecionou-se como corpus uma tirinha de Quino intitulada Fluxograma, observando de que forma as personagens Susanita e Mafalda mobilizam discursos a respeito do ideal feminino, ou dos papeis desempenhados pela mulher. Percebeu-se que, enquanto as falas de Susanita refletem a ideologia patriarcal imperante nas décadas de 1960 e 1970 na Argentina, as enunciações de Mafalda representam a resistência ao sistema tradicional, em que o ser feminino não é apenas visto como corpo-instrumento, mas sobretudo como sujeito-mulher.

Palavras-chave: Relações dialógicas. Corpo-Instrumento. Sujeito mulher. Tirinha

\section{BETWEEN BODY-INSTRUMENT AND SUBJECT WOMAN: DIALOGICAL RELATIONS IN A QUINO'S COMIC STRIP}

\begin{abstract}
This paper delimited as object of study the dialogical relations, central category in the thought of Mikhail Bakhtin, in dialogue with other members of the circle of Bakhtin, like Valentin Volóchinov and Pável Medviédev. For that, a corpus of Quino's comic strip was selected as a corpus, observing how the characters Susanita and Mafalda mobilize discourses about the feminine ideal, or the roles played by the woman. It was noticed that while Susanita's speeches reflect the patriarchal ideology prevailing in the 1960s and 1970s in Argentina, Mafalda's enunciations represent resistance to the traditional system, in which the feminine being is seen not only as a body instrument but above all as subject-woman.
\end{abstract}

Keywords: Dialogical relations. Body-Instrument. Woman subject.

1 Doutorando em Linguística pela programa de Pós-graduação da Paraíba (UFPB). E-mail wildersantana92@gmail.com

2 doutorando em Linguística e Língua Portuguesa (UNESP/Araraquara). E-mail marcus.garcia@unesp.br 


\section{Introdução}

O presente trabalho, tecido sob prisma da Análise Dialógica do Discurso, doravante $\mathrm{ADD}^{3}$, utiliza como categoria bakhtiniana as relações dialógicas, classificadas como relações de sentido que se estabelecem entre enunciados, a partir do momento em que ocorre diálogo - interação - entre sujeitos e/ou discursos. Nessa direcionalidade, "o dialogismo, na perspectiva dos integrantes do Círculo, é considerado o princípio constitutivo da linguagem, em sua dimensão concreta, viva, real." (SANTANA; FRANCELINO, 2018, p. 237). Recorre-se, portanto, aos pressupostos teóricometodológicos de Mikhail Bakhtin (1895-1975), Valentin N. Volóchinov (1895-1936) e Pável N. Medviédev (1891-1938), integrantes do Círculo de Bakhtin, para fundamentação e desenvolvimento das análises, norteando-se pelas relações dialógicas interdiscursivas.

Quanto à linguagem, para Bakhtin (2006 [1979]), constitui-se como uma prática cuja situação histórica e social concretiza-se no momento da atualização dos enunciados. Nesse viés, tal concepção de linguagem é centrada nos interlocutores, apresentando seu caráter responsivo-ativo no ato verbal em que o discurso é produzido. Uma vez que "a enunciação é o produto

3 O termo Análise Dialógica do Discurso (ADD) é cunhado por Beth Brait (2006) para circunscrever um horizonte teórico-metodológico dos estudos dialógicos em terreno brasileiro na medida em que reflete sobre os estudos de Bakhtin e o Círculo. Desse modo, em texto intitulado Análise e Teoria do Discurso, a pesquisadora assevera que: "Sem querer (e sem poder) estabelecer uma definição fechada do que seria essa análise/teoria dialógica do discurso, uma vez que o fechamento significaria uma contradição em relação aos termos que a postulam, é possível explicar seu embasamento constitutivo, ou seja, a indissolúvel relação existente entre língua, linguagens, história e sujeitos que instaura os estudos da linguagem como lugares de produção de conhecimento de forma comprometida, responsável, e não apenas como procedimento submetido a teorias e metodologias dominantes em determinadas épocas" (BRAIT, 2006, p.10). É por meio desse dispositivo teóricometodológico de interpretação que se possibilita examinar a organicidade não apenas do discurso estético, mas também o discurso do cotidiano, no nível ético, cuja contribuição é significativa para compeensão da produção de sentidos nos movimentos da linguagem humana. da interação de dois indivíduos socialmente organizados" (VOLOCHÍNOV 2017 [1929], p. 209), todo e qualquer texto, verbal ou não-verbal, possui natureza social interativa ${ }^{4}$. Em horizonte de pesquisas brasileiras, inserimo-nos no hall de produções que concretizam estudos dialógicos acerca da linguagem (BRAIT, 2006; HAMMESRODRIGUES; ACOSTA PEREIRA, 2019; GERALDI, 2019; ROHLING, 2019).

Nesse sentido, este artigo tem por objetivo analisar, por meio de relações dialógicas, como os discursos proferidos pelas personagens Susanita e Mafalda refletem, respectivamente, a ideologia dominante a respeito do ser feminino e a resistência a esse sistema, em uma tirinha de Joaquim Salvador Lavado, conhecido como Quino. Observa-se como os enunciados mobilizados pelas personagens constituem um embate acerca do ideal feminino no regime ditatorial argentino, o que reflete opiniões de grupos específicos de comunidades brasileira e argentina ${ }^{5}$. Um fato importante a se observar sobre a personagem é que Mafalda "nasce" num período peculiar do governo argentino, visto que se vivia "uma ainda incerta e pouco duradoura democracia liberal” (MOURA, 2012. p.31), pois em 1966, iniciar-se-ia uma ditadura militar.

4 Ao refletir sobre essa questão, no que respeita à perspectiva dialógica do discurso, Santana, em texto intitulado Uma seiva dialógica? (2019) compreende que a natureza dialógica é constitutiva das vivências humanas, as quais são contornadas por efeitos de verdadeiro na medida em que o ser humano é constitutivamente atravessado por essas experiências. Recorre, então, a Buber (1982), para quem "Os domínios da vida dialógica e da vida monológica não coincidem com os do diálogo e do monólogo, mesmo se nestes incluirmos suas formas sem som e sem gesto. Não existem somente grandes esferas da vida dialógica que na sua aparência não são diálogo, mas existe também o diálogo que não é diálogo enquanto forma de vida, isto é, que tem a aparência de um diálogo, mas não a sua essência. Aliás, parece, às vezes, que esta última espécie é a única que ainda existe (p.53). A vida dialógica não é uma vida em que se tem muito a ver com os homens, mas é uma vida em que, quando se tem a ver com os homens, faz-se isto de uma forma verdadeira (p.54). O diálogo entre meros indivíduos é apenas um esboço; é somente entre pessoas que ele se realiza" (BUBER, 1982, p. 53-54).

5 Mafalda é uma personagem relevante, uma vez que se tornou uma voz que compõe a história dos argentinos e que influencia em grande medida o processo de gestação da política e ideologia brasileiras, ao nos fazer refletir sobre problemáticas de ordem política. 
Para análise, selecionamos como corpus uma tirinha intitulada $O$ fluxograma, em que são analisados confrontos enunciativo-discursivos entre Susanita e Mafalda, esta sendo a personagem protagonista das tiras de Quino. Propomo-nos a averiguamos as incidências do ideal patriarcal no discurso de Susanita acerca do papel da mulher, provenientes de determinidades sociais contemporâneas às décadas de 60 e 70 do século XX, assim como o novo paradigma feminino concretizado nas réplicas de Mafalda. Tais enunciações só tem sentido quando confrontadas com as réplicas das outras personagens e as condições sociohistóricas de sua produção e circulação. A protagonista das tirinhas, Mafalda, não apenas representa uma "pequena menina de seis anos que, preocupada com o destino da humanidade, vive questionando o mundo a sua volta de uma forma sutil e perspicaz" (ROSA et al, 2012. p.4), mas sobretudo a porta-voz de um discurso politizado e crítico, projetando e refinando críticas com efeito de humor.

De acordo com Moura (2012), Mafalda é "uma criança que fala aquilo que pensa e por isso coloca os adultos em situação embaraçosa, uma menina de opinião, com uma visão bastante crítica da realidade, sonhadora e contestadora, esta é a pequena grande notável Mafalda" (MOURA, 2012, p. 30). Assim, os comentários e ideias de Mafalda refletem as preocupações políticas e sociais das décadas de 1960 e 1970, ao simbolizar o anticonformismo do ser humano que não se contenta com regimes autoritários estabilizados, ao passo que nutrem perspectivas de mudança sociopolítica.

Em termos estruturais, este trabalho está dividido em 3 seções: a primeira, "Relações dialógicas sob os pressupostos bakhtinianos", traça um percurso das concepções bakhtinianas de dialogismo e relações dialógicas, o que fundamenta os dizeres teóricos deste manuscrito. A segunda seção explicita um estudo sobre o "Gênero discursivo Tira em quadrinhos ou Tirinhas", enquanto a terceira seção é destinada à análise realizada, intitulada "Relações dialógicas: entre corpo-instrumento e sujeito mulher".

\section{Relações dialógicas sob os pressupostos bakhtinianos}

A natureza dialógica da linguagem, como definição teórica, desempenha papel importantíssimo nas obras de Bakhtin e o Círculo. Em textos como "O problema do autor" e "Metodologia das ciências humanas", integrantes da coletânea Estética da criação verbal (2006 [1979]), é possível perceber os posicionamentos de Bakhtin tanto em relação à linguagem quanto o que respeita ao sujeito e suas dimensões socio-históricas. Em Reformulação do livro sobre Dostoiévski reflete o teórico russo sobre a natureza dialógica da consciência consiste na
natureza dialógica da própria vida humana. A única forma adequada de expressão verbal da autêntica vida do homem é o diálogo inconcluso. A vida é dialógica por natureza. Viver significa participar do diálogo: interrogar, ouvir, responder, concordar, etc. Nesse diálogo o homem participa inteiro e com toda a vida: com os olhos, os lábios, as mãos, a alma, o espírito, todo o corpo, os atos. Aplica-se totalmente na palavra, e essa palavra entra no tecido dialógico da vida humana, no simpósio universal. (BAKHTIN, 2006 [1979], p. 348).

O dialogismo, para os estudiosos integrantes do Círculo, é considerado o princípio constitutivo da linguagem, em sua dimensionalidade concreta, real. Nesta perspectiva, segundo Sobral (2009), denomina-se essa concepção de dialógica porque propõe que a linguagem (e os discursos) têm seus sentidos desvelados na/pela presença constitutiva da intersubjetividade (a interação entre subjetividade) no intercâmbio verbal. Dito de outra forma, as situações concretas do exercício da 
linguagem se tornam elementares para a construção de uma multiplicidade de sentidos.

O conceito de relações dialógicas aparece de forma mais desenvolvida em Problemas da poética de Dostoiévski (2005[1963]), particularmente no capítulo 5 "O discurso em Dostoiévski", no escopo da literatura na medida em que Bakhtin incide sobre os romances de Dostoiévski, relacionando a vida à arte. Nesse sentido, problematiza e reacentua os conceitos de linguagem e língua advindos da linguística estruturalista. Desse modo, as relações dialógicas são extralinguísticas (BAKHTIN, 2005 [1963]), ou seja, estabelecem-se numa dimensão que circunscreve o sistema da língua. Nas palavras do filósofo soviético,

As relações dialógicas são irredutíveis às relações lógicas ou concreto-semânticas, que por si mesmas carecem de momento dialógico. Devem personificar-se na linguagem, tornar-se enunciados, converter-se em posições de diferentes sujeitos expressas na linguagem para que entre eles possam surgir relações dialógicas (BAKHTIN, 2005, p. 209, destaques do autor).

Nesse percurso argumentativo, Volóchinov (2017 [1929]), ao tratar da língua em sua natureza real/viva, afirma que esta não é um sistema abstrato de formas linguísticas (fonéticas, gramaticais e lexicais), mas esses elementos linguísticos são a base para compreensão dos elementos extraverbais, em um contexto concreto específico, numa enunciação particular. Nas anotações do teórico, decorrem as seguintes proposições:

1. A língua como sistema estável de formas normativas e idênticas é apenas uma abstração científica que só pode servir a certos fins teóricos e práticos particulares. Essa abstração não dá conta de maneira adequada da realidade concreta da língua.

2. A língua constitui um processo de evolução ininterrupto, que se realiza através da interação verbal social dos locutores.
3. As leis da evolução linguística não são de maneira alguma as leis da psicologia individual, mas também não podem ser divorciadas da atividade dos falantes. As leis da evolução linguística são essencialmente leis sociológicas.

4. A criatividade da língua não coincide com a criatividade artística nem com qualquer outra forma de criatividade ideológica específica. Mas, ao mesmo tempo, a criatividade da língua não pode ser compreendida independentemente dos conteúdos e valores ideológicos que a ela se ligam. A evolução da língua, como toda evolução histórica, pode ser percebida como uma necessidade cega de tipo mecanicista, mas também pode tornar-se "uma necessidade de funcionamento livre, uma vez que alcançou a posição de uma necessidade consciente e desejada.

5. A estrutura da enunciação éuma estruturapuramente social. A enunciação como tal só se torna efetiva entre falantes. $\mathrm{O}$ ato de fala individual (no sentido estrito do termo "individual") $e ́$ um contradictio in adjecto (VOLOCHÍNOV, 2017 [1929], p. 221, grifos dos autores).

Neste prisma de compreensão, diferentemente de Saussure (e dos que se vinculam à perspectiva do objetivismo abstrato), que procurou descentralizar a fala e apenas privilegiou e reconhece a língua como um sistema fechado de formas normativas imutáveis, Volóchinov (2017 [1929]) valoriza o aspecto sócio-discursivo ${ }^{6}$ da fala, a qual está constitutivamente conectada à enunciação. Em termos volochinovianos,

Qualquer que seja o aspecto da expressãoenunciação considerado, ele será determinado pelas condições reais da enunciação em questão, isto é, antes de tudo pela situação social mais imediata.

Com efeito, a enunciação é o produto da interação de dois indivíduos socialmente organizados e, mesmo que não haja um interlocutor real, este pode ser substituído

6 Nos termos de Santana (2018, p. 168-169), "O foco de Medviédev, em busca do "reflexo do horizonte ideológico" (2016 [1928], p. 65), foi acentuar a linguagem poética formalista enquanto tendência ao niilismo artístico, imanentismo e ausência do aspecto sociológico nos estudos literários (2016 [1928]). Nesse contexto, os sentidos múltiplos se dão no entrecruzamento extraverbal (conteúdo), o qual ganha carne (forma) na propriação do linguístico que, o que caracterizaria, de fato, a linguagem poética russa (material)". 
por um representante médio do grupo social ao qual pertence o locutor. A palavra dirige-se a um interlocutor: variará se se tratar de uma pessoa do mesmo grupo social ou não... (VOLÓCHINOV, 2017 [1929], p. 208, grifos do autor).

Na perspectiva de Volóchinov, tanto o aspecto quanto o sentido da palavra que é direcionada a outrem ganha concretude em situações reais na esfera comunicativa da interação discursiva. Além de Bakhtin reconhecer a originalidade da natureza das relações dialógicas, discorre densamente sobre o dialogismo interior. É graças às fronteiras entre enunciados que se chega à compreensão dos diálogos.

A partir dessas considerações acerca da noção de linguagem, percebe-se a necessidade de que haja o diálogo Eu/Outro, o que constitui a primazia das relações dialógicas, que não se reduzem simplesmente às interações face a face, mas a excedem, até em reenunciações de discursos milenares.

\section{Gênero discursivo Tira em quadrinhos ou Tirinhas}

Sobre a noção de gênero discursivo, prestase importância fundamental em todo o trajeto composicional de Mikhail Bakhtin no que respeita ao ensaio Os Gêneros do discurso (2006 [1952-1953]). Nesta produção, é desenvolvida de forma detalhada a concepção de dialogismo, ao tecer diferenciações (s) entre o enunciado concreto (compreendido como unidade da comunicação discursiva) e a oração (entendida como unidade da língua). Em tal produção, o autor aponta especificidades do enunciado que o distinguem da oração, da frase e de outras unidades estruturais, tais como: a alternância entre os sujeitos falantes e relativa estabilidade dos enunciados. Para Santana e Francelino,

O enunciado encontra, em seu curso natural na comunicação discursiva, os enunciados de outrem, já impregnados das intenções e dos pontos de vista desse(s) outro(s), com o qual(is), inevitavelmente, adota uma compreensão responsiva ativa de concordância-discordância, convergência-divergência, tolerânciaintolerância, não necessariamente de forma dicotômica. Portanto, há uma reação à palavra do outro, à visão de mundo do outro, de modo que, ao entrelaçar-se com o discurso alheio, o enunciado adentra um espaço saturado de diferentes posições axiológicas (2018, p. 237).

Nesse direcionamento argumentativo, encontramos sentidos múltiplos nas especificidades do enunciado, uma vez que são caracterizados maximamente pelo princípio constituinte da heterogeneidade, a qual territorializa a dimensão dialógica da linguagem, assim como promove a circunscrição dos sujeitos em camadas reais de existência via a enunciação concreta. Segundo Bakhtin (2016 [1979], p. 54, grifos nossos),

[...] a experiência discursiva individual de qualquer pessoa se forma e se desenvolve em uma interação constante e contínua com os enunciados individuais dos outros. [...] Nosso discurso, isto é, todos os nossos enunciados (inclusive as obras criadas) é pleno de palavras dos outros, de um grau vário de alteridade ou de assimilabilidade, de um grau vário de aperceptibilidade e de relevầncia. Essas palavras dos outros trazem consigo a sua expressão, o seu tom valorativo que assimilamos, reelaboramos, e reacentuamos.

Além do que é proposto no clássico Os gêneros do discurso (BAKHTIN (2016, [1979])7, (em que se foca nos três elementos: forma composicional, conteúdo temático e estilo), recorremos ao texto Peculiaridades do gênero, do enredo e da composição das obras de dostoiévski, em que Bakhtin afirma que "O gênero sempre é e não é o mesmo, sempre é velho e novo ao mesmo tempo [...] O gênero vive do presente mas sempre recorda o seu passado, o seu começo" (2008 [1929], p.121).

Em seu artigo Reflexões sobre os gêneros do discurso, Brait \& Pistori (2012, p. 376) afirmam que Bakhtin (2008 [1929]) traz, na conclusão de Problemas da

7 O texto "Os gêneros do discurso", de Bakhtin, escrito entre 1951-53, aparece na coletânea cuja primeira edição russa é de 1979, e foi traduzido por Paulo Bezerra. Está junto a outros textos no livro "Estética da Criação Verbal". 
poética de Dostoiévski, "importantes afirmações sobre gênero que respondem questões colocadas hoje em relação aos gêneros próprios das novas formas de comunicação". Ainda de acordo com as autoras, estas formas comunicativas engendram por novos valores, assumidos pelo homem contemporâneo, no que tange a tempo/espaço, público/privado, efêmero/duradouro.

A respeito do gênero tira em quadrinhos (ou simplesmente tirinhas), este consiste em um veículo comunicativo de massa. De acordo com Rama e Vergueiro, "as publicações do gênero circulam com uma enorme variedade de títulos e tiragens de milhares ou, às vezes, até mesmo milhões de exemplares, avidamente adquiridos e consumidos por um público fiel, sempre ansioso por novidades" (2004, p. 07). Isso devido à composição desse gênero discursivo, que, em sua maioria, se constitui de no mínimo duas faces: elementos linguísticos e imagéticos, e a parte extra verbal, lugar em que os sentidos múltiplos são gerados, no plano enunciativo.

Quanto aos elementos composicionais estéticos, é constituída de balões, os quais notificam a fala, e a expressão-pensamento dos personagens. $\mathrm{Na}$ perspectiva de Oliveira (2008), os quadrinhos são uma narrativa gráfico-visual, impulsionada por sucessivos cortes, que agenciam imagens, ou seja, "as histórias em quadrinhos constituem um sistema narrativo composto por dois códigos: o visual e o verbal”. (OLIVEIRA, 2008. p.75). Em outras palavras, o gênero tirinha nada mais é do que uma sequência de imagens cujos personagens têm suas falas escritas em balões, sendo então a mescla de registros escritos e imagéticos. Ramos (2011, p. 01), na introdução de seu trabalho sobre "Tira, gênero e hipergênero", assevera:

O "Dicionário de gêneros textuais", de Sérgio Roberto Costa, define história em quadrinhos (ou HQs) como um gênero com três características essenciais: 1) integração entre palavras e imagens; 2) presença do tipo narrativo na maioria dos textos; 3) papel como suporte mais recorrente.

No caso específico da Tira em quadrinhos da Mafalda, para representar a personagem, Quino se utiliza de um autor-criador, ao mobilizar discursos de humor e ironia, características constitutivas do gênero tira em quadrinhos (ou tirinhas). Isso é o que também afirma Oliveira (2008):

\begin{abstract}
As tiras de Quino têm a preocupação com a discussão de certos temas que sugerem críticas sociais. Dessa forma, o humor e a ironia estão presentes nessas narrativas. Pode-se dizer, então, que Quino mostra aos seus leitores suas análises do contexto social histórico- político do momento, levando os mesmos a verem a triste realidade da América Latina bem como de outros países em conflito (OLIVEIRA, 2008, p. 5).
\end{abstract}

Segundo Ávila (2009, p.25), a personagem foi criada com o objetivo de estrelar uma campanha publicitária de uma empresa de eletrodomésticos. Entretanto a campanha não utilizou a personagem e então houve o arquivamento de Mafalda. Algum tempo depois, algumas das tirinhas foram publicadas e caíram no gosto dos leitores.

Então, em 29 de setembro de 1964, é publicado
no jornal semanal Primera Plana que solicita
uma colaboração fixa, quotidiana, satírica e
inovadora que refletisse as inquietações da
época; além disso, discute questões polêmicas
nacionais e internacionais. Justamente, por essa
preocupação inicial, a história da personagem
Mafalda está recheada de fatos e momentos
muito importantes da sociedade argentina e
do contexto mundial das décadas de 60 e 70
(ÁVILA, 2009, p. 25-26).

Por isso, nos seus textos, Quino faz uma análise do contexto histórico-político social do momento em que escreveu, e muitas delas são pertinentes ao momento atual da realidade não só da América Latina, como também de outras regiões em conflito. Tudo isso, é claro, através de sua personagem Mafalda,

personificando a insatisfação frente a uma realidade social e econômica que não busca 
apenas respostas, mas desperta perguntas e inquietações. [...] Mafalda reflete as tendências de uma juventude inquieta. [...] Ela é a porta-voz de todas aquelas questões que os leitores de suas tiras gostariam de ter a coragem de colocar para o mundo, mas que nem sempre conseguem fazê-lo (MOURA, 2012, p.31).

Assim sendo, em nossa análise, pretendemos demonstrar como seus discursos produzem efeitos de sentido de grandes críticas. Para isso, analisaremos suas falas com base na Teoria Dialógica da Linguagem, a fim de vermos nas tirinhas a relação da linguagem com as condições de produção do discurso, que são: o enunciador, o interlocutor, e o contexto histórico - social e ideológico. Na medida em que concordamos com Guerra (2003, p.14), ao afirmar que “o texto é um objeto linguístico-histórico e, a partir disso, visto na perspectiva do discurso; ele não é uma unidade fechada, embora como unidade de análise ele possa ser considerado uma unidade inteira, pois ele tem relação com outros textos", concebemos texto como discurso (BAKHTIN, 2006 [1979]).

A próxima seção consiste na análise de uma tirinha de Quino intitulada O fluxograma, em que é apresentado um diálogo estabelecido entre duas personagens, Mafalda e Susanita. As incidências analíticas não se dão apenas em perspectiva linguística, mas também dialógico-discursiva.

\section{Relações dialógicas: de corpo-instrumento a sujeito mulher}

O corpus é composto por uma tira de Quino, publicada entre décadas de 1960 e 1970 - período da ditadura militar na Argentina. Dentre os assuntos que ganharam visibilidade no cenário da crítica, estava o papel da mulher enquanto sujeito sócio-histórico e cultural, frente às tendências patriarcalistas. Nesse sentido, elencamos uma tira intitulada O fluxograma, a qual nos oportuniza, enquanto leitores responsivos e ativos ${ }^{8}$, perceber as marcas ideológicas presentes nos discursos dessa época, assim como a pulverização de valores e a forte incidência do patriarcalismo nos papeis da mulher, o qual molda-a como corpoinstrumento.

As relações dialógicas se dão, portanto, na análise semântico-ideológica do discurso de Susanita acerca do papel feminino, assim como suas prováveis determinidades sociais. Pretendemos também demonstrar que o conhecimento dos fatores linguístico-imagéticos e extraverbais são necessários para a real compreensão dos sentidos das falas e textos correntes na sociedade. Um exemplo é que tais conhecimentos estão presentes nas camadas discursivas socioideológicas, as quais atravessam o enunciado. Passemos à análise.

\footnotetext{
8 Por leitores responsivos e ativos entendemos sujeitos que interagem com seus outros nas produções dialogais, e são estimulados à compreensão de uma fala viva, de enunciados acompanhados de uma atitude responsiva ativa. É nesse sentido que empreende Bakhtin: "Toda a compreensão é prenhe de resposta e, de uma forma ou de outra, forçosamente a produz: o ouvinte torna-se o locutor". (BAKHTIN, 2006 [1979], p. 271). Na perspectiva do filósofo russo, "A obra, assim como a réplica do diálogo, visa a resposta do outro (dos outros), uma compreensão responsiva ativa, e para tanto adota todas as espécies de formas: busca exercer uma influência didática sobre o leitor, convencê-lo, suscitar sua apreciação crítica, influir sobre êmulos e continuadores, etc. A obra predetermina as posições responsivas do outro nas complexas condições da comunicação verbal de uma dada esfera cultural. A obra é um elo na cadeia da comunicação verbal; do mesmo modo que a réplica do diálogo, ela se relaciona com as outras obras-enunciados: com aquelas a que ela responde e com aquelas que lhe respondem, e, ao mesmo tempo, nisso semelhante à réplica do diálogo, a obra está separada das outras pela fronteira absoluta da alternância dos sujeitos falantes (BAKHTIN, 2006 [1979], p. 279, grifos nossos). Assim, leitores responsivo-ativos são aqueles que interagem discursivamente com a realidade socio-histórica do enunciado e ouvem dialogicamente vozes outras, como um processo constituído pela compreensão responsiva ativa. Eis em que consiste uma atitude responsiva ativa: é quando o sujeito "concorda ou discorda (total ou parcialmente), completa, adapta, apronta-se para executar, etc., e esta atitude do ouvinte está em elaboração constante durante todo o processo de audição e de compreensão desde o início do discurso" (BAKHTIN, 2006 [1979], p. 271).
} 
Figura 1: O fluxograma

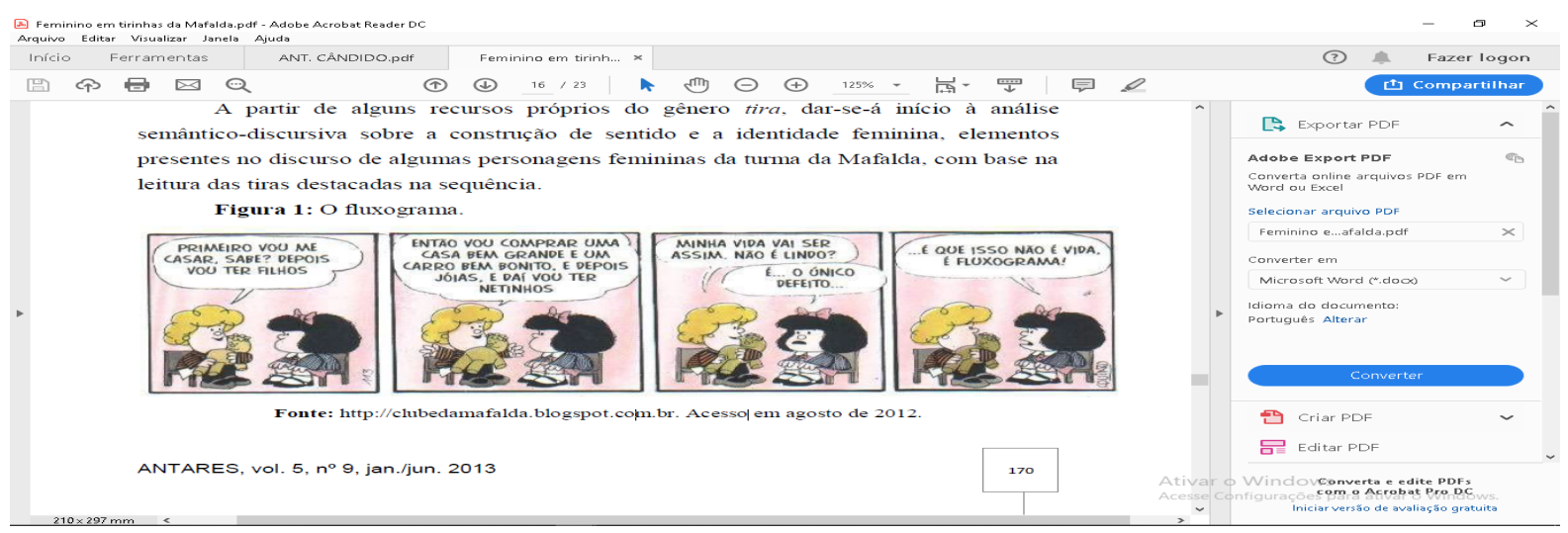

Fonte: http://clubedamafalda.blogspot.com.br. Acesso em fevereiro de 2019.

A tirinha anteposta é formada por um diálogo estabelecido entre Mafalda e Susanita, sua melhor amiga. A composição imagética é caracterizada por tons de rósea claro e branco, como se remetesse o leitor, inicialmente, ao infantil feminino. Quanto ao plano linguístico-discursivo, em que as personagens interagem através da comunicação verbal face a face, foi de nosso interesse averiguar as relações dialógicas e os posicionamentos ideológicos presentes nas enunciações de Susanita e Mafalda. No primeiro quadro da tira, quem primeiro enuncia é Susanita, e aparenta estar dando continuidade a um diálogo em trânsito. A garota está narrando para Mafalda seus projetos para o futuro, tais como o sonho de casar e ter filhos: "Primeiro vou me casar, sabe? Depois ter filhos" e continua no segundo quadro a enunciar: "Então vou comprar uma casa bem grande e um carro bem bonito, e depois joias, e daí vou ter netinhos".

As enunciações de Susanita constituem o reflexo de uma ideologia patriarcal, fundamentada na normatividade de que a mulher deve assumir tais papeis na sociedade para ser bem-vista. Tal pensamento encarna, mesmo que refratadamente, a confissão de Spinoza (2009 [1677]), de que a exclusão das mulheres da esfera política é a realização de um desejo dos homens. Assumindo a obrigação única de casar, ter filhos e ser cuidadora do lar, a mulher é moldada socialmente como um corpo-instrumento, categoria por nós proposta em reconhecimento de que, durante muito tempo, o ser feminino serviu de uso para satisfação objetal/sexual masculina. O corpo-instrumento consiste no papel único de objeto de prazer e servidão que foi assumido pelo ser feminino no decorrer de sua existência, o que remonta à sua exclusão da política e do direito ao conhecimento. Desse modo, leituras sobre a função/utilidade/serventia da mulher no Direito, na Religião e nas Artes, desde a acepção entre patrícios, plebeus e escravos nos permitem classificá-la como um corpo que foi instrumentalizado para uso masculino.

De igual modo, as falas da personagem Susanita remontam às representações impostas de ideais sociais machistas e não igualitários, circunscritos no panorama ideológico do patriarcalismo. Nesse sentido, o desejo de crescer e se projetar em um núcleo familiar tradicional e resumir sua felicidade à ordem ideológica da multiplicação (gerar filhos) implica no reconhecimento de que o homem não é apenas o detentor do poder, mas o provedor que garantirá à mulher condições para que ela assuma o papel único de criadora de seus filhos. Zolin (2013) afirma que, nesse prisma de interpretação, a instituição casamento já existia como uma construção que deveria ser conduzida até o fim da vida de um dos 
parceiros, não importando o tipo de relação que pudessem ter, construção de papeis que norteou parte dos relacionamentos sociais.

Na ótica discursivo-crítica de Delphy (1998), a constante produção doméstica é assegurada gratuitamente pela exploração econômica da mulher pelo homem, apoiando-se na instituição do casamento. Assumindo o papel objetal de sujeito de produção doméstica, a mulher constituiria a base econômica do patriarcado.

Susanita constrói suas enunciações sob a ordem linear casamento $\rightarrow$ filhos como uma réplica de concordância com o próprio sistema sociomatrimonial, cujo discurso hegemônico consistia na união heteronormativa ${ }^{9}$ no propósito primordial da procriação. Para compreender as incidências socioideológicas no processo dialógico arquitetônico desse enunciado recorremos a Winnicott, para quem o casamento foi sempre visibilizado no interior do contexto familiar, cuja necessidade primeira do casal seria ter filhos. $\mathrm{Na}$ perspectiva do pesquisador, "Os casais sem filhos tentam de todos os modos constituir uma família" (...) "Os pais precisam das crianças para desenvolver seu relacionamento (...)" (WINNICOTT, 1997, p. 64).

Medviédev (2016 [1928])10, estudioso e integrante do círculo de Bakhtin, fornece informações valiosas para uma concepção

9 Concordamos com Foster quando este afirma: "Por heteronormatividade, entende-se a reprodução de práticas e códigos heterossexuais, sustentada pelo casamento monogâmico, amor romântico, fidelidade conjugal, constituição de família (esquema pai-mãe-filho(a) (s)). Na esteira das implicações da aludida palavra, temse o heterossexismo compulsório, sendo que, por esse último termo, entende-se o imperativo inquestionado e inquestionável por parte de todos os membros da sociedade com o intuito de reforçar ou dar legitimidade às práticas heterossexuais" (FOSTER, 2001, p. 19). Nesse sentido, a utilização em nosso trabalho reflete práticas que se atualizam na sociedade contemporânea brasileira, ao averiguarmos certo querer-efetuar a sexualidade normalizante, por meio de discursos que circunscrevem a condição homossexual como anormal.

10 Especificamente na obra $\mathrm{O}$ método formal nos estudos literários - Uma introdução crítica a uma poética sociológica, no capítulo "Os elementos da construção artística/O problema do gênero". desse tipo de enunciado em abordagem da materialização ideológica, a qual se dá por meio de enunciados concretos, articulando interior e exterior, "viabilizando a noção de sujeito histórica e socialmente situado" (BRAIT/PISTORI, 2012, p. 373). Caso não averiguássemos os enunciados por meio de relações dialógicas, ou seja, caso não analisássemos os sentidos produzidos mediante o contexto de produção de sua época, "todas estas possibilidades e contextos empregados para encontrar um sentido flutuam neles mesmos, em uma espécie de espaço sem ar, e não estão enraizados em nada de unitário e singular..” (BAKHTIN, 2010 [1920-24], p. 38).

No terceiro quadro, Susanita conclui sua fala endereçando-se a Mafalda, interrogando "Minha vida vai ser assim. Não é lindo?" Mafalda, que permanecia em escuta, expressa seu argumento, por meio de insatisfação, em relações dialógicas de contestação e resistência ao discurso da amiga Susanita. No terceiro e no quarto quadrinhos, a reposta de Mafalda, que demonstra estar pasmada com as opiniões de sua colega assim se concretiza: "É... o único defeito... é que isso não é vida. É fluxograma!"

Nas palavras de Bakhtin (2006d [1979], p. 289),

a fala só existe, na realidade, na forma concreta dos enunciados de um indivíduo: do sujeito de um discurso-fala. O discurso se molda sempre à forma do enunciado que pertence a um sujeito falante e não pode existir fora dessa forma. Quaisquer que sejam o volume, o conteúdo, a composição, os enunciados sempre possuem, como unidades da comunicação verbal, características estruturais que lhes são comuns e, acima de tudo, fronteiras claramente delimitadas. (...) As fronteiras do enunciado compreendido como uma unidade da comunicação verbal são determinadas pela alternância de sujeitos falantes ou de interlocutores.

As opiniões de Mafalda são o reflexo da resistência às imposições hegemônicas da ditadura nas décadas de 60 e 70 , da voz que não concorda com 
as imposições do sistema oficial. Em seu ponto de vista, todo o pensamento de Susanita acerca de seu futuro não consistem em uma existência feliz, ou seja, em uma vida com liberdade de escolhas pessoal e profissional. Ao contrário, todo o panorama visível nas entrelinhas do pensamento de Susanita assumem a função de um fluxograma, ou seja, um esquema de diretrizes regulamentadoras para sua própria vida, o qual maquia todo um sistema de reprodução de padronização patriarcalista. Tal percepção nos remonta a uma asserção de Bakhtin, o qual afirma que "[...] cada enunciado é pleno de ecos e ressonâncias de outros enunciados com os quais está ligado pela identidade do campo de comunicação discursiva. Cada enunciado deve ser visto antes de tudo como uma resposta aos enunciados precedentes [...]" (BAKHTIN, 2006d [1979], p. 297 [grifos do autor]). Ao refletirmos sobre a linguagem como ato11, recorremos a Sobral (2009, p. 24), para quem

\begin{abstract}
$\mathrm{O}$ ato como conceito é o aspecto geral do agir humano, enquanto os atos são seu aspecto como particular, concreto. Todos os atos têm em comum alguns elementos: um sujeito que age, um lugar em que esse sujeito age, e um momento em que age. Isso se aplica tanto aos atos realizados na presença de outros sujeitos como os atos realizados sem a presença de outros sujeitos, aos atos cognitivos que não tenham expressão linguística, etc. Falar de ato, portanto, pressupõe dois planos, um plano de generalidade, dos atos em geral, e um plano de particularidade, de cada ato particular, planos esses que estão necessariamente interrelacionados.
\end{abstract}

Dialogicamente, os embates discursivos das personagens espelham o campo ideológico concernente ao período ditatorial na Argentina e no Brasil, em que a construção da identidade

$11 \mathrm{Na}$ ótica de Sobral (2009), a filosofia do ato ético de Bakhtin constitui uma proposta de estudar o agir humano, um modus para se compreender, teórica e praticamente o modo como os indivíduos agem no mundo concreto: "[...] um mundo social e histórico e, portanto, sujeito a mudanças, não apenas em termos de seu aspecto material, mas na maneira de os seres humanos o conceberem simbolicamente, isto é, o de representarem por meio de alguma linguagem, e de agirem nesses termos em circunstâncias específicas" (SOBRAL, 2009, p. 24). feminina estava sendo moldada sob parâmetros sociais patriarcais. De um lado Susanita é a portavOz do tradicionalismo, e de outro, Mafalda materializa em seu discurso a bandeira da resistência ao tradicionalismo, da intelectualidade e de um feminino com mais liberdade, cultura, e escolhas que transcendem o desejo por alto poder aquisitivo.

Por meio de relações dialógicas, torna-se perceptível que o confronto instaurado por Quino no diálogo entre as duas personagens constitui polos adversos de pensamento a respeito do papel da mulher enquanto corpo-instrumento e sujeito social. Tanto as expressões faciais e movimentos quanto as enunciações de Susanita reproduzem o modelo vigente do feminino, tradicional, de unicamente dona de casa, cuidadora dos filhos e zeladora do lar. Essa abordagem instrumentaliza o corpo da mulher, projetando-o socialmente como um objeto de satisfação do ser masculino.

Por outro lado, as réplicas de Mafalda inauguram no trajeto enunciativo um novo prisma de interpretação sociocultural a respeito do ser feminino, não como um indivíduo escravo de ações pensamentos, mas sobretudo como um sujeito pensante, livre, ou seja, um novo molde para a identidade da mulher. Tal posicionamento reacentua pesquisas e reflexões que influenciam vozes ativas sobre a mulher condicionada à história social e cultural das ciências, tais como Jordanova (1993), Harding (1996), Bleier (1988), as quais problematizam os papeis impostos socialmente para (des)legitimar a divisão homem/mulher na constituição política e científica. O sujeito feminino simbolizado pelas enunciabilidades de Mafalda, que projeta sua vida para além de um fluxograma, não nega a possibilidade das funções e daqueles desejos evidentes na normatização de conduta tradicional, mas ultrapassa-o, condicionando as mulheres a, além de donas de casa e mães, serem excelentes profissionais, viajantes, representantes políticosocio-culturais e influenciadoras de mentes. 
Sob efeito de humor, os sentidos plurais presentes na tira transcendem a estrutura interna do texto, sendo necessário aos leitores/analistas estabelecerem relações dialógicas entre os enunciados verbais e não verbais com a história, sem a qual não seria possível perceber as críticas realizadas pelo autor, Quino, ao sistema político hegemônico argentino no período ditatorial.

A nova mulher sublimada na enunciação de Mafalda não é o indivíduo corpo-instrumento, moldado e padronizado por saberes cristalizados em regime patriarcal, mas evidencia o sujeito mulher, que se posiciona criticamente diante da sociedade. As discursivizações que gerenciam a identidade feminina a partir das personagens Susanita e Mafalda se dão por meio de relações dialógicas, em que as réplicas de Mafalda nos dão a possibilidade de compreender o novo paradigma que se instaurava sobre o ser feminino.

\section{Considerações Finais}

Estudos construídos sob prisma da Análise Dialógica do Discurso vêm contribuindo significativamente para os estudos linguísticodiscursivo-estéticos, bem como impulsionados pesquisadores a tecerem olhares críticos sobre os enunciados selecionados para análise(s). $\mathrm{Na}$ medida em que averiguamos a incidência discursiva e os atravessamentos enunciativos que constituem o gênero, por meio de relações dialógicas, foi possível transcender a materialidade contextual imediata, e compreender os sentidos plurais presentes na tira em quadrinhos de Quino O fluxograma.

Através das análises foi possível investigar como as personagens construídas por Quino, Susanita e Mafalda, representaram polaridades ideológicas a respeito do ser feminino concernentes ao período ditatorial na Argentina. Sob a égide do pensamento de Bakhtin e o Círculo, esperamos que este trabalho possa consistir em ruptura com o fechamento científico, assim como um dispositivo de (des)continuidades metodológicas. Esclarecemos, por fim, que este manuscrito não contém palavras últimas, fechadas nem homogêneas, mas réplicas e provocações para o surgimento de novas produções.

\section{Referências}

ÁVILA, Graciane de. 1968: Ideologia e contestação através das tiras da Mafalda. UFRGS: Porto Alegre, 2009.

BAKHTIN, M. O discurso em Dostoiévski. In: BAKHTIN, M. Problemas da poética de Dostoiévski. Rio de Janeiro: Forense, 2005 [1963], p. 207-310.

BAKHTIN, Mikhail. O problema do autor. In: BAKHTIN, Mikhail. Estética da criação verbal. Trad. Paulo Bezerra. 4. ed. São Paulo: Martins Fontes, 2006a [1979]. p. 173-194.

BAKHTIN, Mikhail. Os gêneros do discurso. Organização, tradução, posfácio e notas de Paulo Bezerra; notas da edição russa de Serguei Botcharov. São Paulo: Editora 34, 2016 [1979].

BAKHTIN, Mikhail. Reformulação do livro sobre Dostoiévski. In: BAKHTIN, Mikhail. Estética da criação verbal. Trad. Paulo Bezerra. 4. ed. São Paulo: Martins Fontes, 2006c [1979], p. 337-358.

BAKHTIN, Mikhail. Metodologia das ciências humanas. In: BAKHTIN, Mikhail. Estética da criação verbal. Trad. Paulo Bezerra. 4. ed. São Paulo: Martins Fontes, 2006d [1979]. p. 393-410.

BAKHTIN, Mikhail. Peculiaridades do gênero, do enredo e da composição das obras de dostoiévski. In: BAKHTIN, Mikhail. Problemas da Poética de Dostoiévski. Trad. Paulo Bezerra. $4^{a}$ edição, revista. Rio de Janeiro: Ed. Forense Universitária, 2008 [1929], p. 115-206.

BAKHTIN, Mikhail. Para uma filosofia do ato responsável. Trad. Valdemir Miotello e Carlos 
Alberto Faraco. São Carlos: Pedro \& João Editores, 2010 [1920-24].

BLEIER, R. (ed.). Feminist Approaches to Science. New York: Pergamon Press, 1986. 212p.

BRAIT, Beth; PISTORI, Maria Helena Cruz. A produtividade do conceito de gênero em Bakhtin e o Círculo. Alfa, São Paulo, 56 (2): 371-401, 2012.

BRAIT, Beth. Análise e Teoria do Discurso. In: BRAIT, B. (Org.). Bakhtin: Outros Conceitoschave. São Paulo: Contexto, 2006. p. 9-31.

BUBER, M. Do diálogo e do dialógico. Perspectiva, 2006 [1982].

DELPHY, Christine. "Les femmes dans les études de stratifi cations [1977]". Reeditado in Delphy, Christine. L'ennemi principal, t.1, Économie politique du patriarcat, Paris, Syllepse "Nouvelles questions féministes", 1998, 293p

FOSTER, David W. Consideraciones sobre el estudio de la heteronormatividade en la literatura latinoamericana. Letras: literatura e autoritarismo, Santa Maria, n. 22, jan./jun. 2001.

GERALDI, João Wanderley. Portos de Passagem. 4. ed. São Paulo: Martins Fontes, 1997.

GUERRA, Vânia Maria Lesclano.Reflexão sobre alguns conceitos da Análise do Discurso de linha francesa. Ensaios e Ciência. Campo Grande (MS), v. 7, n.1, p. 217-232, 2003.

HAMMES-RODRIGUES, Rosangela; ACOSTA PEREIRA, Rodrigo. Apresentação. In: HAMMESRODRIGUES, Rosangela; ACOSTA PEREIRA, Rodrigo (Orgs). Estudos dialógicos da linguagem e pesquisa em linguística aplicada. São Carlos: Pedro e João Editores, 2016. p. 9-16.

HARDING, Sandra. Rethinking Standpoint Epistemology: What is 'Strong Objectivity', in Evelyn Fox Keller, Helen Longino (Eds.). Feminism and Science, Oxford University Press, 1996, p.23548.

JORDANOVA, Ludmilla. Gender and the
Historiography of Science, British Journal of the History of Science, 1993, n.26, p.469-83.

MOURA, Edivânia Cérgia de Jesus. Análise do discurso contestatório nas tirinhas da Mafalda. . Monografia. Universidade Estadual de Goiás. Campus Jussara, 2012

MEDVIÉDEV, Pável Nikoláievitch. O Método Formal nos estudos literários: introdução a uma poética sociológica. Tradutoras: Sheila Camargo Grillo e Ekaterina Vólkova Américo - $1^{\mathrm{a}}$ ed. São Paulo: Contexto, 2016.

MOREIRA E SILVA, Carla Letuza. A emancipação feminina em Mafalda: uma análise discursiva de tiras. In: Revista do Programa de Pós-Graduação em Estudo de Linguagens. UNEB. n. 04. Salvador, 2012

OLIVEIRA, Mônica Lopes Smiderle de. A ironia como produção de humor e crítica social: uma análise pragmática das tiras de Mafalda. Dissertação de Mestrado. UFES. Vitória, 2008.

QUINO. O fluxograma. In: http://clubedamafalda. blogspot.com.br. Acesso em fevereiro de 2019.

RAMA, Angela; VERGEIRO, Waldomiro. Como usar as histórias em quadrinhos na sala de aula. São Paulo: Editora Contexto, 2004.

RAMOS, Paulo. Tiras, gênero e hipergênero: como os três conceitos se processam nas histórias em quadrinhos? Anais do VI Simpósio Internacional de Gêneros Textuais. Natal: Universidade Federal Rio Grande do Norte, 2011.

ROHLING, Nívea. A atuação do professor de Língua Portuguesa discursivizada na educação à distância: uma escuta dialógica. In: HAMMESRODRIGUES, Rosangela; ACOSTA PEREIRA, Rodrigo (Orgs). Estudos dialógicos da linguagem e pesquisa em linguística aplicada. São Carlos: Pedro e João Editores, 2016. p. 9-16.

ROSA, Douglas Corrêa da; et al., Análise do discurso na tirinha da personagem "Mafalda" In: Identidade Científica, v. 3, n. 1, Presidente Prudente. 2012. p. 72-83. 
SANTANA, Wilder Kleber Fernandes de. FRANCELINO, Pedro Farias. A representação linguístico-discursiva de Jesus Cristo em seu sermão sobre o cumprimento do amor a partir do evangelho segundo são Mateus. Revista da Anpoll v. $1, \mathrm{n}^{\circ} 45$, p. 233-247, Florianópolis, Maio/Ago. 2018.

SANTANA, Wilder Kleber Fernandes de. Uma seiva dialógica? In: SANTANA, Wilder Kleber Fernandes de. Relações linguísticas e axio(dia) lógicas: sobre linguagem e enunciação. Vol. 1. Pessoa: Ideia, 2019.

SOBRAL, Adail. Do dialogismo ao gênero: as bases do pensamento do Círculo de Bakhtin. Campinas, São Paulo: Mercado de Letras, 2009.

SPINOZA. Tratado político. Tradução de Diogo Pires Aurélio. São Paulo: M. Fontes, 2009 [1677].

VOLÓCHINOV, Valentin. A Interação Discursiva. In: VOLOCHÍNOV, V. N. (círculo de Bakhtin). Marxismo e filosofia da linguagem - Problemas fundamentais do método sociológico na ciência da linguagem. Tradução de Sheila Grillo e Ekaterina Vólkova Américo - Ensaio introdutório de Sheila Grillo. 1. ed. São Paulo: Editora 34, 2017b [1929]. p. 201-226.

WINNICOTT, Donald. A Família e o desenvolvimento individual. $2^{\mathrm{a}}$ ed. Trad. Cipolla M. B. São Paulo: Martins Fontes, 1997.

ZOLIN, Lúcia Osana. A literatura de autoria feminina brasileira no contexto da pósmodernidade. Ipotesi, Juiz de Fora, v. 13, n. 2, p. 105 - 116, jul./dez. 2009.

Submissão: maio de 2020 .

Aceite: outubro de 2020. 